\section{Snowy Owl nest failures caused by blackfly attacks on incubating females}

\author{
Roar Solheim ${ }^{1}$, Karl-Otto Jacobsen ${ }^{2}$, \\ Ingar Jostein Øien ${ }^{3}$, Tomas Aarvak ${ }^{3} \&$ \\ Petteri Polojärvi ${ }^{4}$
}

\begin{abstract}
${ }^{1}$ Agder Natural History Museum and Botanical Garden, Postboks 1887 Gimlemoen, NO-4686 Kristiansand, Norway; e-mail roar.solheim@kristiansand.kommune.no; ${ }^{2}$ Norwegian Institute for Nature Research, Framsenteret, NO-9296 Tromsø, Norway; ${ }^{3}$ Norwegian Ornithological Society, Sandgata 30b, NO-7012 Trondheim, Norway; ${ }^{4}$ Metsähallitus, Natural Heritage Services, Lapland, Peuratie 15, FI-99400 Enontekiö, Finland
\end{abstract}

Abstract. Blackflies (Simuliidae) have been shown to influence birds negatively in several ways. In 2011, during a peak lemming year, we found that two of 28 nests of Snowy Owls Bubo scandiacus in Northern Norway and Finland failed due to blackfly attacks on the incubating female. The observations also suggest that adult survival may be influenced by these insects. The owls' choice of breeding habitat can be decisive in their vulnerability to blackflies.

\section{INTRODUCTION}

Nesting success of raptors in the high Arctic varies greatly, usually due to fluctuating prey populations and unpredictable weather conditions. Here we report for the first time that blackflies (Simuliidae) cause nest failures and, in principle, fatal injuries to individual nesting females of an owl species, the Snowy Owl Bubo scandiacus.

Blackflies are a well-known nuisance to people (Currie \& Adler 2008). Some species are more harmful than others, their bites inducing heavy swellings and even allergic reactions. Blackflies are classified as ornithophilic or mammalophilic, based on the form of the female tarsal claw, double claws being an adaptation for grasping feathers and feeding from birds (Currie \& Hunter 2009). Of 70 blackfly species from Alaska, USA and the Yukon Territory, 36\% were ornithophilic (Currie 1997). Blackfly attacks have been shown to be detrimental to Great Horned Owl chicks Bubo virginianus, however most probably through infestations with parasites Leucocytozoon spp. transferred by the biting flies (Hunter et al. 1997, Hellgren et al. 2008)). Rohner et al. (2000) found that Great Horned Owls changed their preferred roost locations from trees to open ground in late summer, as an adaptation to reduce blackfly attacks. Blackfly attacks did however not influence the condition of adults and nestlings of hole-nesting Blue Tits Cyanistes caeruleus (Tomás et al. 2008). The most detrimental effect on breeding birds by blackflies is reported from a wetland colony of Common Gull Larus canus, with behavioural changes in adults, loss of clutches and even mortality of chicks and adults (Bukacinski \& Bukacinska 2000). So far, allergic reactions to blackfly bites have not been reported in birds (Currie \& Hunter 2009).

\section{OBSERVATIONS}

In Fennoscandia, 2011 was the best breeding year for Snowy Owls since 1978, when several hundred pairs probably bred in Sweden and Norway (Lindberg \& Wiklund 1991, Jacobsen 2005). Finland did not have any records that year. In 2011 more than 50 nests or breeding attempts were documented, with 42 in Norway, 10 in Finland and two in Sweden (Jacobsen et al. 2012). In total we visited and studied 18 nests in Norway and 10 in Finland. All were situated in the low alpine zone (Moen 1998). In each country we encountered one nest where the female abandoned her brood due to heavy blackfly attacks.

\section{Nest 1, Norway}

In Norway one nest was found in Karasjok , Finnmark, on 24 June. The nest was located on the top of an escarpment by a small mountain lake, and contained seven chicks and three eggs, together with several freshly killed Norway lemmings Lemmus lemmus. At first all chicks seemed to be dead, but on closer inspection it turned out that three of them still showed signs of life, though severely hypothermic. An adult female was flushed from the vegetation about 10 metres from the nest. Her abdomen was dark and bloodstained, and she flew unsteadily and plunged into the lake. We managed to retrieve her from the water after approximately 15 minutes. She was cold and almost lifeless and her eyes were totally clogged by clotted blood (Figure 1). A closer inspection revealed no open wounds or signs of attack by predators, as we first suspected, but the skin of her head, neck and chest was dark from subcutaneous hemorrhage, and clotted with blood (Figure 2).

Our attention was directed towards saving the female owl when found, and no attempts were made to collect any blackflies for closer inspection. The way bites were distributed all over the skin of the owl, beneath and between feathers could however only have been delivered by blackflies. Mosquitos only target bare skin, and never crawl in between hairs or feathers. Also, blackflies were noted here by the field personnel.

The female was brought back to the base camp, warmed, cleaned and fed for two days. She was then equipped with a satellite transmitter and released 


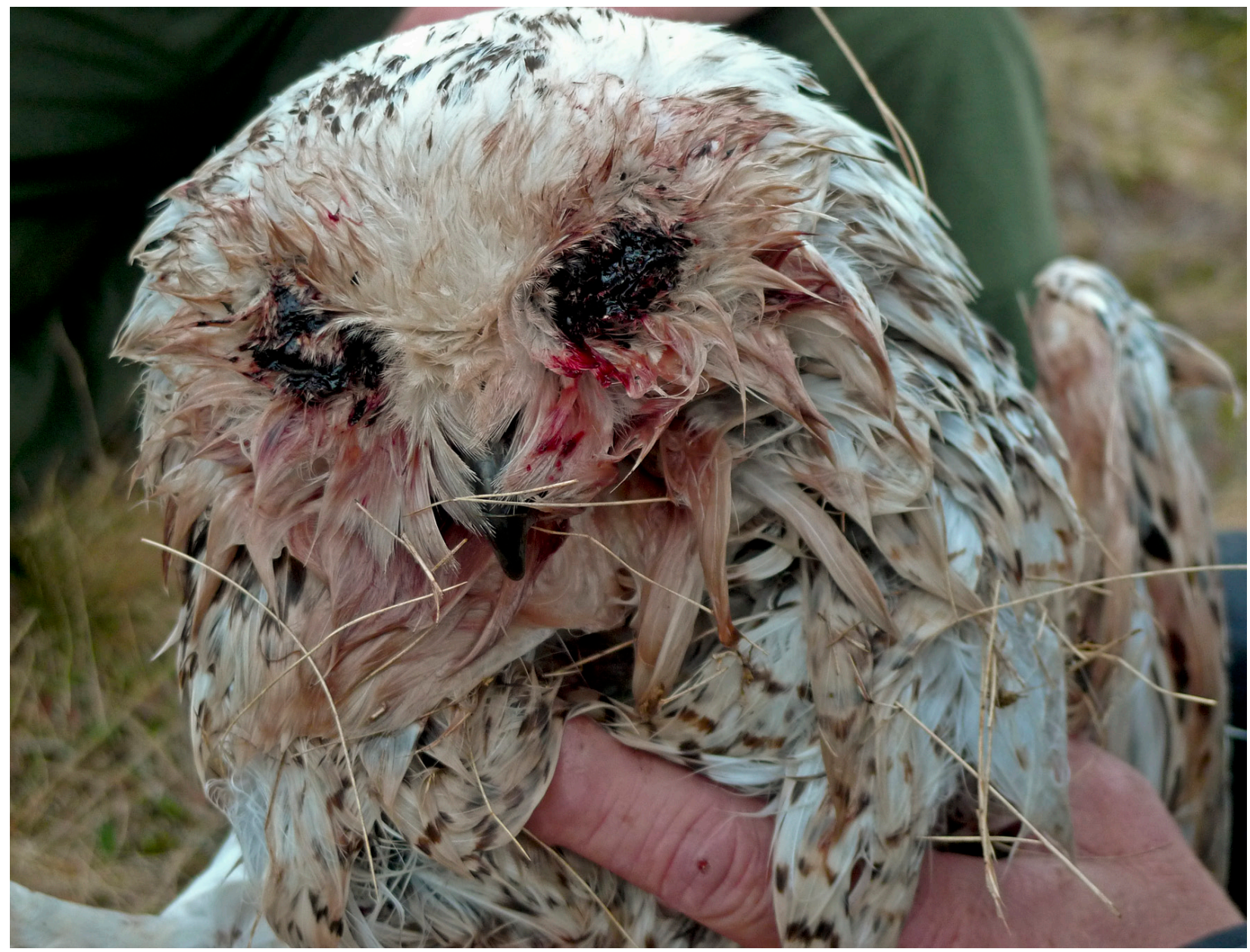

Figure 1 . The Karasjok female, with badly clotted and totally shut eyelids. Photo: T. Aarvak.

some $30 \mathrm{~km}$ away from the nest. It was however not possible to save the three chicks that showed some signs of life when found, so the whole clutch perished. The transmitter has sent signals since the female was released (still active by February 2013), proving that she survived and moving in the same pattern as ten other adult Snowy Owls equipped with satellite transmitters in 2011 (Jacobsen et al. 2012).

\section{Nest 2, Finland}

In Finland one nest in Utsjoki municipality was visited, also on June 24. The brooding female did not appear to be in good condition. Her eyes were totally blocked with clotted blood (Figure 3). The other six incubating Snowy Owl females in this area left their nests when the observer was at a distance of at least 100 metres, while this female stayed at the nest until the observer was closer than $10 \mathrm{~m}$ from her. The nest contained 2 eggs and 2 chicks. The female took off when the observer approached her again, but landed rather clumsily after flying approximately $100 \mathrm{~m}$ away. Her chicks did not seem to be in good condition. There were no prey items at this nest, and the observer suspected at the time that this might have been a secondary female of a bigamist male. The nest was visited again by another observer a few days later, and the female had then abandoned the brood. The other six Snowy Owl nests in the same area were however successful, in the sense that the chicks had left the nest scrapes and hid independently in the surroundings.

\section{DISCUSSION}

It is likely that the female in the Norwegian nest would have died without our intervention, suggesting that blackflies potentially could affect adult mortality directly. The total nest failure of two out of 28 studied nests also shows that at least $7 \%$ of nests failed due to blackflies, a significant proportion of the potential production in 2011. In northern Finland, blackflies have been found to be a nuisance to Black Grouse Tetrao tetrix during summer (Ojanen et al. 2002), and gregarious behaviour during summer may be an adaptation to reducing attacks on individual birds (Rätti et al. 2006). Red-tailed Hawks Buteo jamaicensis in North America are reported to be harassed by blackflies, and chicks are believed to have jumped out from their nest cliffs prematurely because of such blackfly attacks (Smith et al. 1998, Currie \& Hunter 2009). Blackflies 


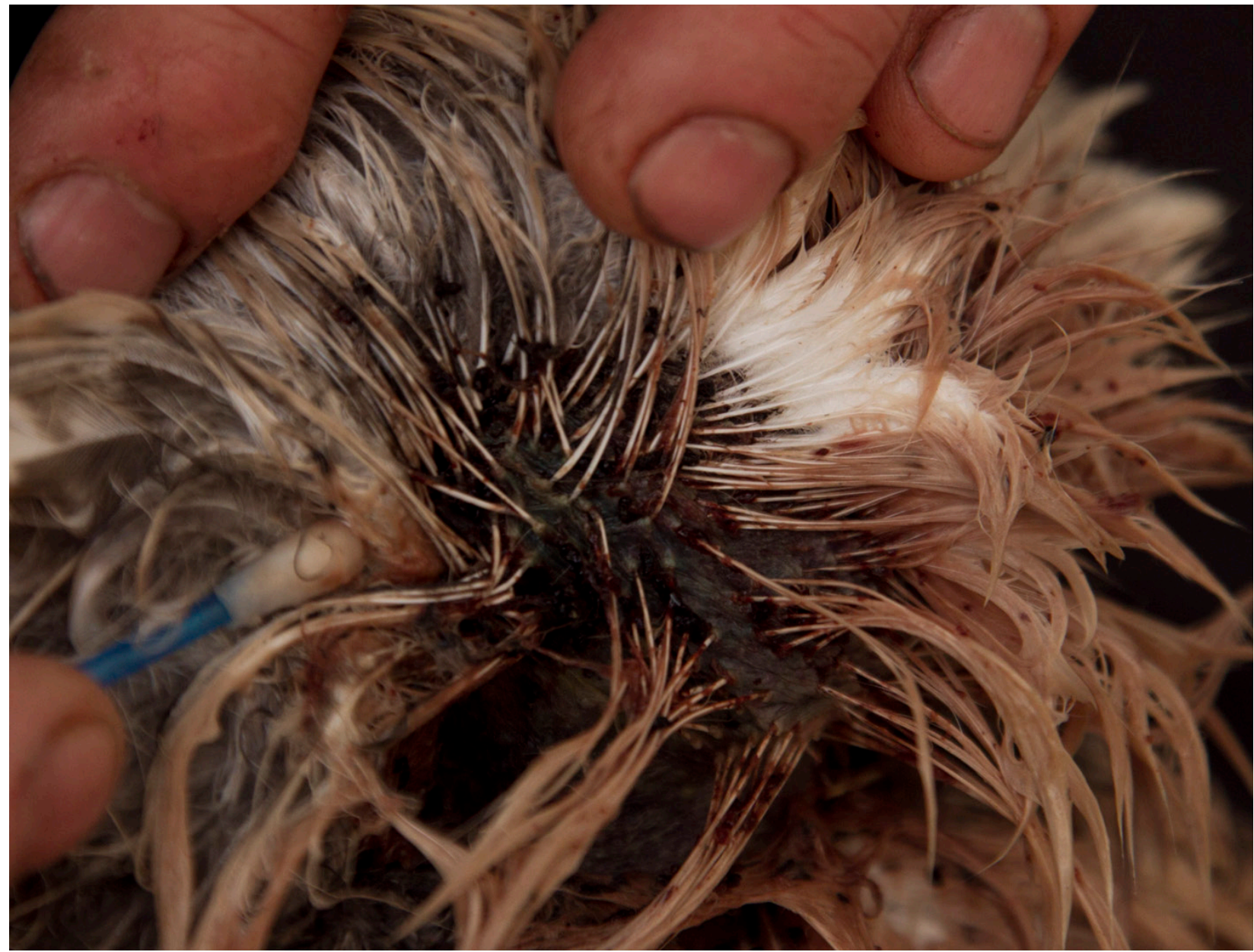

Figure 2. Side of head of the Karasjok female, showing subcutaneous hemorrhage and clotted blood. Photo: R. Solheim/K.O. Jacobsen.

usually attack the featherless parts of the birds, such as eyelids, cere, corners of beak, auricular openings, and other bare skin parts which they can reach, and eyelids may be so heavily attacked that they are swollen and shut (Currie \& Hunter 2009).

We have in Norway never encountered owls in our long term studies of Tawny Owl Strix aluco, Ural Owl Strix uralensis, Great Grey Owl Strix nebulosa, Tengmalm's Owl Aegolius funereus or Pygmy Owl Glaucidium passerinum, with blackfly infestations and with the consequence of failed breeding. In Barrow, Alaska, Denver Holt has studied several hundred Snowy Owl nests for the last twenty years. He reported never to have seen Snowy Owls driven off their nests because of insect attacks (D. Holt pers. comm.). The same is reported from Wrangel Island (Russia) by Irina Menyushina (pers. comm.). In Finland, Pertti Saurola (pers. comm.) reports a late breeding Ural Owl with her eyelids almost closed because of blackfly attacks, however her brood did not fail.

Both nests with the attacked Snowy Owl females were situated in more brush-like habitats than normally used by breeding Snowy Owls in Fennoscandia. The nest in Norway was located near a small lake, not far from a river inlet. The habitat along the lake banks was also bushier than what was recorded for the other nests visited in Norway this summer. The surroundings of the nest held patches of knee-high dwarf birches Betula nana (Figure 4). The nest itself was however open and not concealed by this vegetation. The location of the failed nest in Finland also deviated from the successful nests in the same area by being placed at a lower altitude as compared to the other nests, with a small stream close by. In Norway Snowy Owl nests are most often found at higher altitudes, without any growth of trees or willows. Exceptionally high populations of Norwegian lemmings or voles during winter 2010/2011 may have initiated the owls' breeding attempt in these low-lying habitats.

Mosquitos are a well-known summer nuisance to both animals and people in the Arctic, but they never seem to drive birds away from their nests. Since the female Snowy Owl in Norway spent some time in the cold water, we were unable to judge whether her exhausted state was primarily caused by the blackflies or by the chilling effect of the water. However, the heavy blood clotting around her eyes had already made her unable to take care of the brood. It probably also 


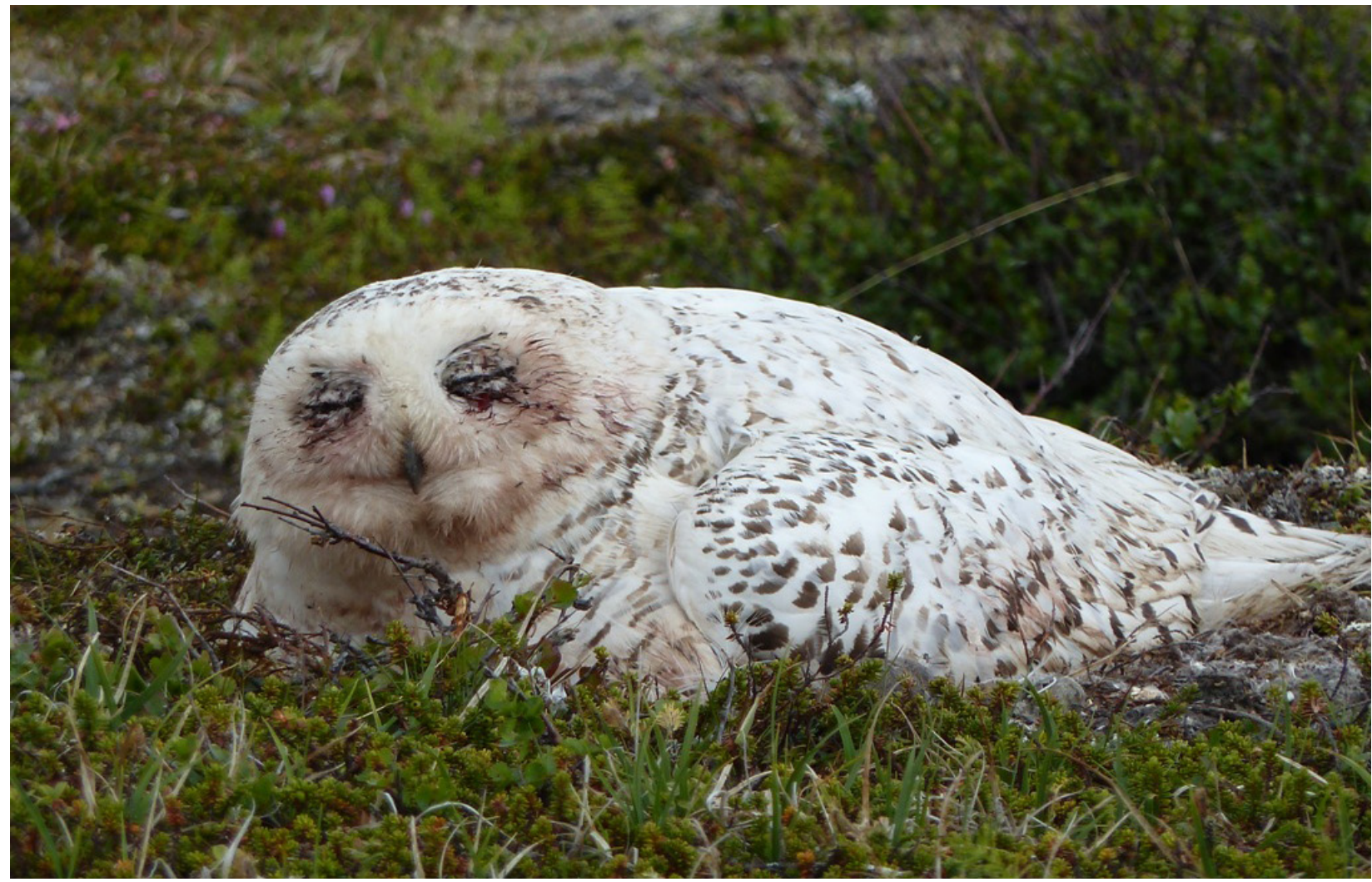

Figure 3. The Utsjoki female on her nest, with closed eyelids clotted with blood from blackfly attacks. Photo: P. Polojärvi.

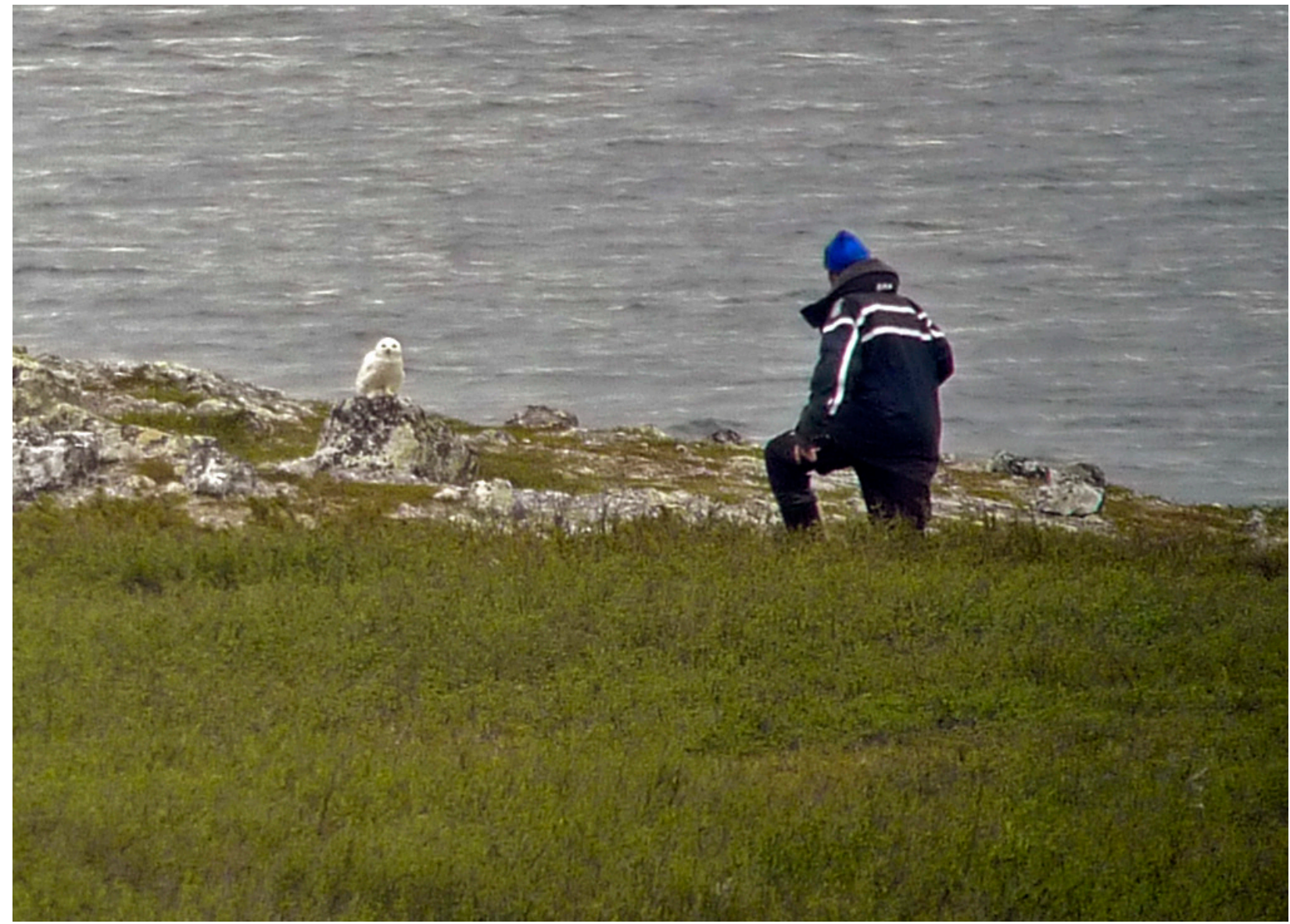

Figure 4. Dwarf birch vegetation at the Karasjok nest site. The male is present in the picture. Photo: T. Aarvak. 
affected her flight ability since she flew unsteadily and plunged into the lake. Watson (1957) describes that Snowy Owl nestlings are often hassled by mosquitos, especially smaller chicks not able to hide under older siblings or the brooding female. Mosquitos particularly attacked the eyelids (up to ten individuals on each eyelid at a time), and the owlets tried to get rid of them by blinking and headshaking. Blackfly bites are considerably more harmful, causing skin lesions with increased vascularization, local oedema, subcutaneous hemorrhage, and even local tissue necrosis among other harmful effects (Hunter et al. 1997, Smith et al. 1998). Blackflies may be more local than mosquitos, and are typically found closer to water. Although we did not try to determine the species of the attacking blackflies, they were quite large. The larvae of these large blackflies live in running streams, while larvae of smaller blackflies are found in lakes and ponds. The proximity of the owls' nests to running streams, and lower elevation hindering wind from blowing the insects away, may be the main reasons for these two Snowy Owls falling victims to the insects. This demonstrates that the smallest creatures may cause havoc, even to the top predators of the Arctic. We presume that this may be a contributing factor determining the nesting habitat preference in Snowy Owls in Fennoscandia, which seems to be poorer and more barren alpine tundra than in other parts of the species' breeding range. This is also a concern for the future, given a warming climate, thawing of tundra habitats and extended growth of vegetation within the Arctic biome.

\section{REFERENCES}

Bukacinski, D. \& Bukacinska, M. 2000. The impact of mass outbreaks of black flies (Simuliidae) on the parental behavior and breeding output of colonial Common Gulls (Larus canus). Annales Zoologici Fennici 37: 43-49.

Currie, D.C. 1997. Blackflies (Diptera: Simuliidae) of the Yukon, with reference to the black fly fauna of northwestern North America. Pp. 563-614 in: Downes, J.A. \& Danks, H.V. (eds.): Insects of the Yukon. Biological Survey of Canada (Terrestrial Arthropods), Ottawa.
Currie, D.C. \& Adler, P.H. 2008. Global diversity of black flies (Diptera: Simuliidae) in freshwater. Hydrobiologia 595: 469-475. DOI 10.1007/s10750-007-9114-1

Currie, D.C. \& Hunter, D.B. 2009. Black Flies (Diptera: Simuliidae). Pp. 537-545 in: Atkinson, C.T., Thomas, N.J. \& Bruce-Hunter, D. 2009: Diseases of Wild Birds. Wiley \& Sons, Iowa.

Hellgren, O., Bensch, S. \& Malmqvist, B. 2008. Bird hosts, blood parasites and their vectors - associations uncovered by molecular analyses of blackfly blood meals. Molecular Ecology 17: 1605-1613.

Hunter, D.B., Rohner, C. \& Currie, D.C. 1997. Mortality in fledgling Great Horned Owls from black fly (hematophaga and leucocytozoonosis). Journal of Wildlife Diseases 33: 486-491.

Jacobsen, K.-O. 2005. Snøugle (Bubo scandiacus) i Norge. Hekkeforekomster i perioden 1968-2005. NINA rapport 84. 35 s. (In Norwegian with an English summary).

Jacobsen, K.-O., Øien, I. J., Solheim, R. \& Aarvak, T. 2012. Det store snøugleåret 2011. Vår Fuglefauna 35: 12-18. (In Norwegian)

Lindberg, P.\& Wiklund C.G. 1991. Bubo scandiacus fjälluggla. ArtDatabanken, SLU: 2012-03-29. http://www.artfakta. se/Artfaktablad/Bubo_Scandiacus_100093.pdf. (In Swedish).

Moen, A. 1998. Nasjonalatlas for Norge: Vegetasjon. Statens kartverk, Hønefoss

Ojanen, U., Rätti, O., Adler, P.H., Kuusela, K., Malmqvist, B. \& Helle, P. 2002. Blood feeding by black flies (Diptera: Simuliidae) on the Black Grouse (Tetrao tetrix) in Finland. Entomologica Fennica 13: 153-193.

Rohner, C., Krebs, C. J. Hunter, D. B. \& Currie, D. C. 2000. Roost site selection of Great Horned Owls in relation to black fly activity: an anti-parasite behavior. Condor 102: 950-955.

Rätti, O., Ojanen, U. \& Helle, P. 2006. Increasing group size dilutes black fly attack rate in Black Grouse. Ornis Fennica 83: 86-90.

Smith, R.N., Cain, S.L., Anderson, S.H., Dunk, J.R. \& Williams, E.S. 1998. Blackfly-induced mortality of nestling Red-tailed Hawks. Auk 115: 368-375.

Tomás, G., Merino, S., Martínez-de la Puente, J., Moreno, J, Morales, J. \& Lobato, E. 2008. Determinants of abundance and effects of blood-sucking flying insects in the nest of a hole-nesting bird. Oecologia 156: 305-312.

Watson, A. 1957. The behavior, breeding and food-ecology of the Snowy Owl Nyctea scandiaca. Ibis 99: 419-462.

Received 24 February 2013. Accepted 2 April 2013. 